\title{
Levels of Circulating Biomarkers at Rest and after Exercise in Coronary Artery Disease Patients
}

\author{
V. DANZIG ${ }^{1}$, B. MÍKOVÁ ${ }^{2}$, P. KUCHYNKA ${ }^{1}$, H. BENÁKOVÁ ${ }^{3}$, T. ZIMA $^{3}$, O. KITTNAR $^{4}$, \\ J. ŠKRHA ${ }^{5}$, A. LINHART ${ }^{1}$, M. KALOUSOVÁ ${ }^{3}$ \\ ${ }^{1}$ Second Department of Medicine, Department of Cardiology and Angiology, First Faculty of \\ Medicine, Charles University and General University Hospital, Prague, Czech Republic, ${ }^{2}$ Railway \\ Hospital, Prague, Czech Republic, ${ }^{3}$ Institute of Clinical Chemistry and Laboratory Diagnostics, \\ First Faculty of Medicine, Charles University and General University Hospital, Prague, Czech \\ Republic, ${ }^{4}$ Institute of Physiology, First Faculty of Medicine, Charles University, Prague, Czech \\ Republic, ${ }^{5}$ Third Department of Medicine, First Faculty of Medicine, Charles University and \\ General University Hospital, Prague, Czech Republic
}

Received February 12, 2009

Accepted June 18, 2009

On-line August 12, 2009

\section{Summary}

As traditional risk factors are unable to fully explain the pathogenesis of coronary artery disease (CAD), novel mechanisms became a target of many investigations. Our aim was to study the response of selected markers to physical exercise. High-sensitive C-reactive protein (hs-CRP), matrix metalloproteinases 2 and 9 (MMP-2, MMP-9), advanced oxidation protein products (AOPP), soluble receptor for advanced glycation end-products (SRAGE), pregnancy-associated plasma protein $A$ (PAPP-A), E-selectin, vascular endothelial growth factor (VEGF) and B-type natriuretic peptide (BNP) levels were measured in serum of 21 CAD patients and in 22 healthy controls at rest and after exercise bicycle stress test performed up to the maximal tolerated effort. At rest, hs-CRP, AOPP, MMP-9 and BNP were significantly elevated in the CAD patients as compared with controls. In contrast, P-selectin was significantly lower in $C A D$ patients and a tendency to lower levels of SRAGE was noted. After exercise MMP-9 and BNP, increased significantly in both groups. In conclusions, CAD patients have elevated hs-CRP, AOPP, MMP-9 and BNP - novel markers related to cardiovascular risk or left ventricular overload. MMP-9 and BNP increase significantly with exercise in both healthy individuals and CAD patients.

\section{Key words}

Coronary artery disease - Inflammation - Metalloproteinases • Natriuretic peptides $\bullet$ Oxidative stress

\section{Corresponding author}

Marta Kalousová, Institute of Clinical Chemistry and Laboratory Diagnostics, $1^{\text {st }}$ Faculty of Medicine and General University Hospital, Charles University, Karlovo nám. 32, 12111 Prague 2, Czech Republic. Fax: +420 224962848.

E-mail: marta.kalousova@seznam.cz,mkalousova@hotmail.com

\section{Introduction}

Although coronary artery disease (CAD) mortality decreases due to primarily preventive measures and success in therapeutical field, it still remains the most frequent cause of death in developed countries. (Cífková and Škodová 2002). In the last decade the research efforts were focused on better understanding of pathogenetic mechanisms and development of novel noninvasive methods to detect early stages of coronary atherosclerosis (Pohost et al. 2000) and identifying subjects at high risk for destabilization of coronary plaques (Aschermann 2004). The presence of "classical" risk factors such as smoking, hypertension, dyslipidemia or diabetes mellitus (Racek and Racková 2002) are unable to explain the whole risk of $\mathrm{CAD}$ and its complications. Novel biochemical markers of risk factors were developed to assess subclinical inflammation, oxidative stress, endothelial dysfunction and ventricular overload. 
AGEs (Advanced Glycation End-products) result from non-enzymatic glycation and oxidative stress protein modification. RAGEs is a multi-ligand type I transmembrane glycoprotein potentially involved in several pathological processes (Bucciarelli et al. 2002) including atherogenesis. Deleterious effects mediated by AGEs are prevented in part by this receptor which in vivo occurs as soluble RAGE (sRAGE). It was repeatedly shown that the level of sRAGE is decreased in CAD and in hypertensive patients (Geroldi et al. 2005).

AOPP (Advanced Oxidation Protein Products) were described as proteins modified by chlorinated oxidants (Witko-Sarsat et al. 1996) and subsequently identified as a risk factor for coronary atherosclerosis (Kaneda et al. 2002).

PAPP-A (Pregnancy Associated Plasma ProteinA) is a zinc metalloproteinase used for screening of Down syndrome and also a marker of acute coronary syndromes (Bayes-Genis et al. 2001). Its concentration increases in the presence of unstable coronary plaques.

MMPs (Matrix Metalloproteinases) constitute a family of endopeptidases that are involved in the breakdown of extracellular matrix and in cancerogenesis and cardiovascular diseases (Parks 1998). MMP-2 together with MMP-9 are involved in degradation of collagen, elastin and fibronectin, and influence the production of several other molecules (McQuibban et al. 2000). The increase in MMPs activity was shown to be associated with the progression of atherosclerotic plaques to their rupture (Beaudeux et al. 2004).

E- and P-selectins mediate initial interaction of leukocytes and thrombocytes with endothelial cells (Shimizu et al. 1991), a reaction playing a role in pathogenesis of many cardiovascular pathological processes. Their soluble components reflect their turnover and may be readily assessed as markers of endothelial injury and thrombosis.

Vascular Endothelial Growth Factor (VEGF) is an important regulator of angiogenesis and vasculogenesis. While processes of vasculogenesis occur during embryonic period, angiogenesis is also activated during the whole life in processes associated with neovascularization (Neufeld et al. 1999).

BNP (B-type Natriuretic Peptide) is a sensitive marker of both left and right ventricular overload (Maisel et al. 2001). BNP is currently used in diagnosing congestive heart failure and stratifying the risk of patients with pulmonary embolism.

High-sensitivity C-reactive protein (hs-CRP) was shown to be associated with increased risk of coronary atherosclerosis. It appears that CRP is not only a marker but an active mediator of atherogenesis (Sung et al. 2003).

Although all above mentioned biochemical parameters are established markers of atherogenesis, unstable plaque presence, ischemia or heart failure, relatively little is known about their immediate response to exercise in healthy individuals and patients with known coronary artery disease. This information is of potential clinical relevance as stress-induced changes, if present, may significantly influence patients' risk stratification. The aim of our study was to analyze the effect of a standard exercise stress test on selected novel cardiovascular biochemical markers (Stern 2002).

\section{Patients and Methods}

\section{Study population}

In the group of patients with coronary artery disease we included 21 patients (18 men and 3 women) of the average age $65 \pm 7$ years. All patients had established CAD defined as confirmed history of either myocardial infarction or percutaneous coronary intervention or aortocoronary bypass grafting or angiographically documented coronary disease (presence of at least one $\geq 50 \%$ stenosis of proximal major coronary artery) (Hess et al. 2006). Patients who had recently (in last 3 months) suffered from acute coronary syndrome (ACS), patients with stenosis of the main arterial trunk of left coronary artery or its equivalent and patients with chronic coronary syndrome class 3 and 4 angina pectoris were not included in the study. All generally recognized contraindications to exercise tests were also respected (Stern 2002). All CAD patients received recommended therapy including ACE inhibitors, statins and low dose $(100 \mathrm{mg})$ acetylsalicylic acid. All patients were invited to withdraw all antianginal treatment (calcium channel blockers, beta-blockers, longacting nitrates) at least $24 \mathrm{~h}$ before the test.

The control group included 22 otherwise healthy individuals ( 17 men and 5 women) of the mean age $30 \pm 5$ years. All subjects were enrolled from a group of individuals undergoing stress testing to measure their physical performance (e.g. employer-initiated preventive programs). Only subjects with clinically and electrically negative exercise test were evaluated.

The study was approved by local institutional ethical committee and all subjects have given their informed consent prior to entering the study. 
Table 1. Demographic and clinical parameters of study populations.

\begin{tabular}{lcc}
\hline & CAD patients & Healthy controls \\
\hline & $\mathrm{n}=21$ & $\mathrm{n}=22$ \\
Male/female ratio & $18 / 3$ & $17 / 5$ \\
Age (years) & $65 \pm 7^{* * *}$ & $30 \pm 5$ \\
Diabetes mellitus & $(51-81)$ & $(22-55)$ \\
Smokers & 5 & 0 \\
Myocardial infarction & 4 & 0 \\
Percutaneous coronary intervention & 10 & 0 \\
Coronary artery bypass graft & 7 & 0 \\
Blood pressure at rest (mmHg) & 5 & 0 \\
Blood pressure after exercise (mmHg) & $126 \pm 19 / 71 \pm 16$ & $238 \pm 31 / 65 \pm 14$ \\
Maximum exercise workload (W) & $18 \pm 40 / 71 \pm 16$ & $275 \pm 37$ \\
Heart rate at rest (beats/min) & $150 \pm 9^{* * *}$ & $77 \pm 12$ \\
Maximum heart rate (beats/min) & $76 \pm 12$ & $179 \pm 12$ \\
\hline
\end{tabular}

Data are expressed as mean $\pm \mathrm{SD}$, (range). ${ }^{* * *} \mathrm{p}<0.0001$ CAD vs. controls.

Table 2. Classical biochemical markers related to cardiovascular risk.

\begin{tabular}{lcc}
\hline & CAD patients & Healthy controls \\
\hline & $\mathrm{n}=21$ & $\mathrm{n}=22$ \\
Glucose $(\mathrm{mmol} / \mathrm{l})$ & $6.64 \pm 2.47^{* * *}$ & $4.59 \pm 0.63$ \\
Uric acid $(\mathrm{mmol} / \mathrm{l})$ & $381 \pm 107^{* *}$ & $286 \pm 82$ \\
Cholesterol $(\mathrm{mmol} / \mathrm{l})$ & $4.71 \pm 0.89$ & $4.62 \pm 0.63$ \\
HDL cholesterol (mmol/l) & $1.25 \pm 0.34$ & $1.37 \pm 0.34$ \\
LDL cholesterol (mmol/l) & $2.53 \pm 0.93$ & $2.72 \pm 0.56$ \\
Triacylglycerols $(\mathrm{mmol} / \mathrm{l})$ & $2.13 \pm 1.17^{* *}$ & $1.37 \pm 0.77$ \\
High-sensitivity CRP $(\mathrm{mg} / \mathrm{l})$ & $2.96 \pm 3.09^{* *}$ & $1.19 \pm 0.81$ \\
\hline
\end{tabular}

$* * \mathrm{p}<0.02, * * * \mathrm{p}<0.0001$ CAD vs. controls.

\section{Design of the study}

Venous blood samples at baseline were taken in patients after $30 \mathrm{~min}$ of rest at least. All patients were invited not to perform any vigorous exercise before the baseline blood sampling. Blood pressure of the patients was taken by the sphygmomanometric method and their resting 12-lead ECG with standard electrode placement in modification by Mason and Likar was recorded before the exercise test.

The bicycle exercise test was performed using $50 \mathrm{~W}$ starting load which was afterwards gradually increased by stages lasting $3 \mathrm{~min}$ and exercise workload increasing by $50 \mathrm{~W}$. The ECG curve was continuously monitored and graphically recorded at the end of each minute along with blood pressure measurement. Exercise was terminated when the predicted heart rate maximum was achieved (determined as 220 - age) or when limiting symptoms occurred. (In the group of patients in CAD the reason for ending of the test was also a rise in blood pressure above 260/130 $\mathrm{mm} \mathrm{Hg}$ and horizontal ST depressions of $4 \mathrm{~mm}$ and more). Five minutes after the end of exercise blood sample was collected for evaluation of stress induced changes in laboratory parameters.

\section{Laboratory parameters}

Blood samples were centrifuged for $10 \mathrm{~min}$ at $1450 \mathrm{~g}$ and serum was frozen at $-20{ }^{\circ} \mathrm{C}$. Analyses of samples were performed within six months. 
Table 3. Changes in the parameters studied after the exercise, comparision CAD patients with healthy controls.

\begin{tabular}{|c|c|c|c|c|}
\hline & \multicolumn{2}{|c|}{ CAD patients } & \multicolumn{2}{|c|}{ Healthy controls } \\
\hline & before the exercise & after the exercise & before the exercise & after the exercise \\
\hline$P A P P-A$ & $8.6 \pm 3.0$ & $8.7 \pm 2.1$ & $8.3 \pm 2.6$ & $8.0 \pm 3.2$ \\
\hline$(m U / l)$ & $8.3(6.4-10.0)$ & $8.1(7.3-9.4)$ & $8.7(6.4-10.4)$ & $8.4(5.5-10.2)$ \\
\hline$A O P P$ & $111.3 \pm 46.6^{*}$ & $127.5 \pm 60.8^{x x}$ & $82.8 \pm 46.3$ & $82.8 \pm 30.1$ \\
\hline$(\mu \mathrm{mol} / \mathrm{l})$ & $102.6(73.8-141.6)$ & $107.6(89.2-164.4)$ & $72.3(55.2-83.1)$ & $78.9(63.9-90.7)$ \\
\hline$R A G E$ & $1578 \pm 864$ & $1999 \pm 1624$ & $1824 \pm 744$ & $2349 \pm 1601$ \\
\hline$(n g / l)$ & $1452(1087-1806)$ & $1606(908-2164)$ & $1711(1360-2252)$ & $1741(1239-3140)$ \\
\hline$M M P-2$ & $239.8 \pm 60.2$ & $241.0 \pm 60.4$ & $236.0 \pm 48.6$ & $248.3 \pm 52.5$ \\
\hline$(\mu g / l)$ & $224.0(189.4-300.4)$ & $224.0(202.0-296.2)$ & $238.3(191.6-283.6)$ & $246.3(206.0-299.4)$ \\
\hline$M M P-9$ & $742.3 \pm 378.8^{*}$ & $892.6 \pm 459.9^{\mathbf{a}}$ & $565.6 \pm 273.8$ & $768.7 \pm 348.9^{b}$ \\
\hline$(\mu g / l)$ & $652.2(536.7-920.7)$ & $813.8(537.4-1093.9)$ & $512.7(396.3-634.3)$ & $751.1(473.2-922.9)$ \\
\hline$B N P$ & $111 \pm 88^{* * *}$ & $150 \pm 117^{x \times, b}$ & $32 \pm 27$ & $53 \pm 44^{\mathrm{a}}$ \\
\hline$(n g / l)$ & $98(30-172)$ & $169(32-217)$ & $24(16-38)$ & $40(30-58)$ \\
\hline sE-selectin & $35.5 \pm 20.7$ & $37.5 \pm 22.8$ & $29.2 \pm 13.2$ & $29.7 \pm 13.6$ \\
\hline$(\mu g / l)$ & $31.8(16.8-51.5)$ & $36.5(17.8-54.9)$ & $24.5(18.0-41.3)$ & $25.7(20.9-39.9)$ \\
\hline sP-selectin & $148.3 \pm 53.2^{*}$ & $146.6 \pm 48.6$ & $190.1 \pm 63.3$ & $193.2 \pm 90.1$ \\
\hline$(\mu g / l)$ & $149.3(99.5-189.3)$ & $120.8(113.4-175.3)$ & $195.5(146.5-248.0)$ & $205.3(121.7-241.7)$ \\
\hline$V E G F$ & $217.4 \pm 122.2$ & $227.9 \pm 152.4$ & $197.6 \pm 110.8$ & $226.1 \pm 123.5$ \\
\hline$(n g / l)$ & $187.7(127.8-291.9)$ & $167.8(143.0-277.6)$ & $168.7(131.4-268.6)$ & $176.3(136.2-313.6)$ \\
\hline
\end{tabular}

Results are expressed as mean $\pm \mathrm{SD}$, median (interquartile range). $* \mathrm{p}<0.05, * * * \mathrm{p}<0.0001 \mathrm{CAD}$ vs. controls before the exercise; ${ }^{\times \times} p<0.01$ CAD vs. controls after the exercise; ${ }^{a} p<0.01,{ }^{b} p<0.001$ effect of the exercise.

PAPP-A and hs-CRP were measured by TRACE (Time Resolved Amplified Cryptate Emission) on the KRYPTOR analyser (BRAHMS GmbH, Henningsdorf, Germany) using standard kits (BRAHMS GmbH, Henningsdorf, Germany).

sRAGE, MMP-2, MMP-9, (all kits RD Systems, USA), P-selectin, E-selectin and VEGF (Biosource, USA) were assessed with standard ELISA (enzyme linked immunosorbent assay) kits.

AOPP were determined spectrophotometrically according to Witko-Sarsat (Witko-Sarsat et al. 1996). Concentration of AOPP is expressed in $\mu \mathrm{mol} / 1$ referred to the calibrator.

BNP was measured with chemiluminiscent method (CLIA) using standard kits (Merck, USA) on automated analyzer Access, Beckman Counter, USA.

Other routine biochemical parameters were determined by standard clinical-chemistry methods recommended by IFCC (International Federation of Clinical Chemistry).

\section{Statistical analysis}

All values are given as mean $\pm \mathrm{SD}$. Comparisons of continuous variables between the studied groups were performed using unpaired t-test in normally distributed parameters and Mann-Whitney test in presence of skewed distribution. Paired t-test and Wilcoxon paired t-test were used to examine the influence of exercise on laboratory parameters within the study groups. All analyses were performed using MedCalc 9.3 (MedCalc Software Comp. Mariakerke, Belgium).

\section{Results}

Principal demographic data and parameters of the exercise are shown in Table 1. The tolerance of exercise in the group of CAD patients was significantly lower than in the control group in which the average maximum recorded exercise workload $275 \mathrm{~W}$ is exceedingly high, proving good physical efficiency of controls.

Routine biochemical characteristics of both studied groups are listed in Table 2. Table 3 depicts studied non-traditional markers related to cardiovascular risk in both groups before and after the exercise. At rest, hs-CRP, AOPPs, MMP 9, and BNP were elevated in the 


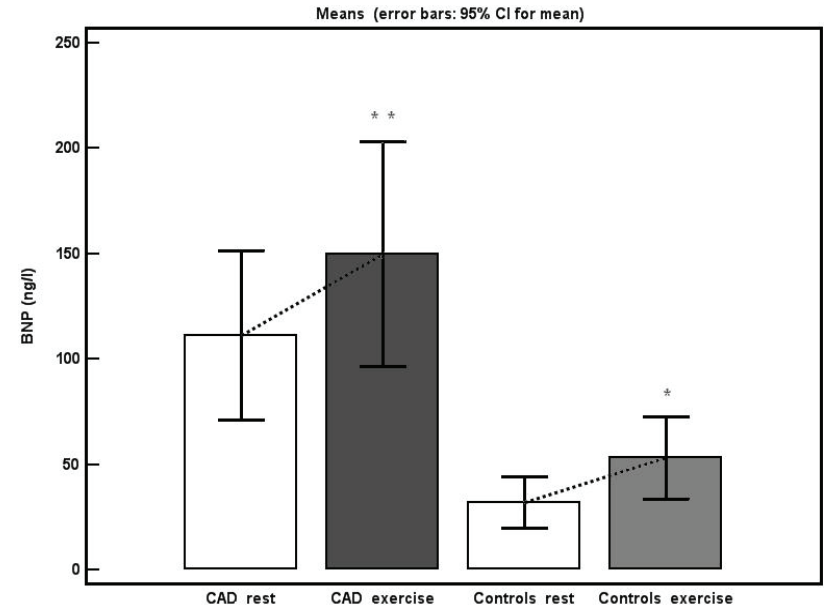

Fig. 1. Influence of exercise on plasma BNP. * $p<0.01$, $* * p<0.001$

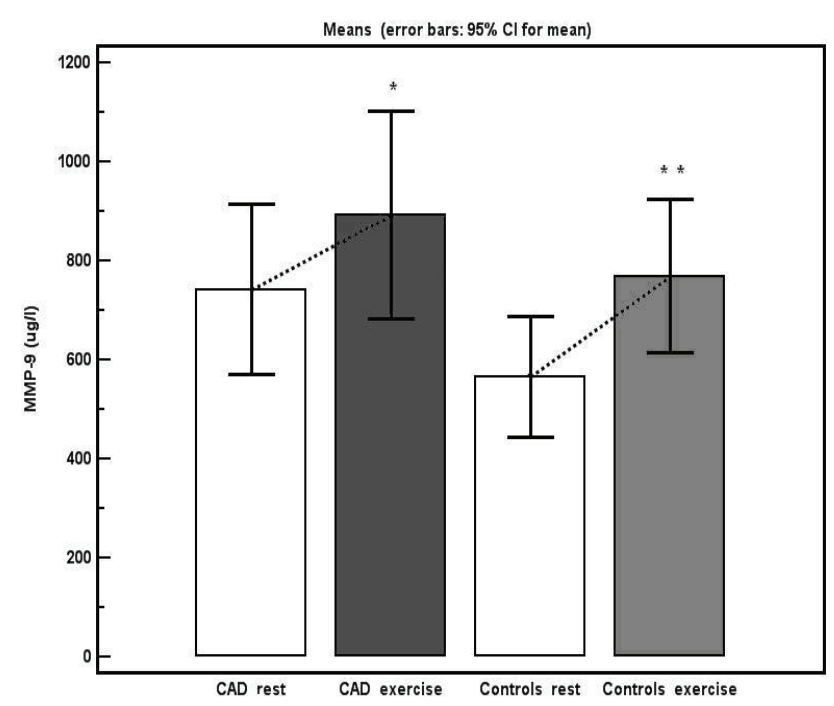

Fig. 2. Influence of exercise on MMP-9 levels. * $p<0.01$, $* * p<0.001$

patients group as compared to controls ( $p<0.02, p<0.05$, $\mathrm{p}<0.0001$, respectively). On contrary, P-selectin was decreased $(p<0.05)$ and a non-significant trend to lower levels of sRAGE was observed in CAD patients.

After exercise MMP-9 and BNP increased significantly in both groups (Figs 1 and 2). After the exercise, the difference in AOPP and BNP levels between the studied groups was still significant, while the MMP-9 concentrations did not differ statistically. Both baseline and post-stress levels of PAPP-A, MMP-2, E-selectin and VEGF were similar in both study groups. In order to avoid the effect of hemoconcentration on the evaluation, we have corrected all values for the albumin content. However, no change in the statistical evaluation was found.

\section{Discussion}

This study shows elevated hs-CRP, AOPP, MMP-9 and BNP and decreased P-selectin and tendency to lower sRAGE in coronary artery disease patients. However, the principal study finding is the significant influence of acute exercise on MMP-9 and BNP levels in both CAD patients and healthy subjects.

Exercise is physiologically connected to a certain degree of damage of skeletal muscles and connective tissue, which leads to activation of tissue metalloproteinases (MMP) and to increased expression of cytoadhesive molecules (selectins) and inflammatory substances (TNF $\alpha$, IL6, CRP) (Carmeli et al. 2005, Signoreli et al. 2003). The elevation of these substances is usually influenced by the exercise intensity. In contrast to long-term physical activity, which leads to reduction of parameters of inflammation, the short-term exercise was shown to be associated with their elevation (Brixius et al. 2008).

The difference in AOPP level between the CAD group and healthy controls was an expected result. The change during the exercise was not statistically significant and the difference between both studied groups remained significant also after the exercise. As the elevation of AOPP caused by exercise was described only in those cases when the exercise was linked to hypoxemia (Pialoux et al. 2006), thus minimal changes in AOPP could be explained by the fact that most patients in our CAD group were previously successfully revascularized. We observed a tendency to lower sRAGE values in the group of CAD patients. This observation is in agreement with published data (Nakamura et al. 2007, Falcone et al. 2005). However, in contrast to other studies, the difference between CAD and control subjects did not reach the statistical significance. This might be due to small number of studied subjects. Our study is the first showing minimal if any immediate response of sRAGEs induced by the acute exercise.

The increase of MMP-9 level in CAD patients in comparison to controls is in agreement with the results of Wu et al. (2005) who described the elevation of matrix metalloproteinases on relatively large number of $\mathrm{CAD}$ patients compared to patients with microvascular angina (coronary syndrome $\mathrm{X}$ ) and healthy controls. Only limited data evaluating the influence of exercise on MMP-9 levels were published. Suhr et al. (2007) demonstrated that maximum after-exercise elevation occurred after a longer interval from the end of the 
exercise. The demonstration of immediate exerciseinduced elevation of MMP-9 is difficult to explain by increased expression of genes of MMP-9 (Büttner et al. 2007). However, exercise is associated with prompt leukocyte increase which may produce many substances, including MMP-9.

Important but expected differences were found in BNP levels between the study groups. Elevation of BNP within the context of increased wall stress is physiologically present during the exercise. It should be noted that we have shown that exercise induced a substantial increase also in healthy individuals. Although in CAD patients or patients with left ventricular dysfunction the elevation of BNP is usually more clearly expressed, we observed an important elevation of BNP after exercise even in CAD patients with clinically and electrically negative stress test (Win et al. 2005). Foote et al. (2004) as well as Vanzetto et al. (2007) suggested more than double increase in treadmill test sensitivity without loss of its specificity when BNP was taken into account. In both cases nuclear cardiology methods were used for correlation with the analysis of BNP in blood samples. These authors explain the increase of BNP by the elevation of wall stress during exercise mainly in ischemic myocardium. As our study shows the physiological character of BNP increase after exercise even in healthy individuals with excellent physical performance, BNP as a tool for detection of ischemia should be evaluated with caution taking into account this phenomenon.

In agreement with the observation from the large PREVEND study (Geluk et al. 2008) we found highly significant differences in basal levels of hs-CRP between patients with CAD and control group. This difference existed in spite of the fact that we did not include patients who recently suffered from the acute coronary syndrome into the group of CAD patients (Geluk et al. 2007). As previously described, chronic forms of CAD are associated with elevated hs-CRP in about $20 \%$. This number increases up to $70 \%$ of cases in patients with unstable angina pectoris (Ridker 2003). The difference in hs-CRP observed in our study may be in part explained by the differences of overall physical performance of our study groups. This hypothesis is supported by observations of Kullo et al. (2007) who demonstrated in asymptomatic men that hs-CRP is inversely correlated with the maximal oxygen consumption and the maximal working capacity.
The absence of a pronounced difference in VEGF when comparing the studied groups as well as the resting and post-exercise states in both groups is in line with the data that exercise positively influences angiogenesis, which, however, is not directly given by the VEGF elevation, but by influencing of the VEGF rate and antiangiotically functioning endostatin.

\section{Study limitations}

The main limitation of our study is the important age difference between the groups. However, the objective of the study was to constitute a control group free of CAD. If older patients were recruited, we would probably need to perform more invasive testing including the coronary angiography to eliminate the presence of serious coronary disease. This approach would be difficult to justify in otherwise healthy asymptomatic individuals. Additionally, in our previously published papers we included older controls and observed similar values for PAPP-A as well as for sRAGE (Kalousová et al. 2003, Kalousová et al. 2007).

\section{Conclusions}

CAD patients have elevated several nontraditional markers related to cardiovascular risk. Moreover, we demonstrated that MMP-9 and BNP increase significantly with exercise in both CAD patients and healthy controls. However, after exercise only BNP remains significantly higher in $\mathrm{CAD}$ patients than in healthy controls. These observations are of potential clinical relevance and should be taken into account when setting up preanalytical conditions for blood sampling in CAD patients. The physiological elevation of BNP in healthy controls indicates that its use in diagnosing CAD in adjunction to stress testing should be made with caution and only important elevations should be considered as pathological.

\section{Conflict of Interest}

There is no conflict of interest.

\section{Acknowledgements}

The study was supported by research project MSM 0021620807. The authors are thankful to Dr. Soukupová, Mrs. Hudcová, Mrs. Miškovská and Mrs. Nožičková for technical assistance. 


\section{References}

ASCHERMANN M: Ischemic heart disease (in Czech). In: Kardiologie. Galén, Praha, 2004, pp 344-348.

BAYES-GENIS A, CONOVER CA, OVERGAARD MT, BAILEY KR, CHRISTINSEN M, HOLME DR Jr, VIRMANI R, OXVIG C, SCHWARZ RS: Pregnancy-associated plasma protein A as a marker of acute coronary syndromes. $N$ Engl J Med 345: 1022-1029, 2001.

BEAUDEUX JL, GIRAL P, BRUCKERT E, FOGLIETTI MJ, CHAPMAN MJ: Matrix metalloproteinases, inflammation and atherosclerosis: therapeutic perspectives. Clin Chem Lab Med 42: 121-131, 2004.

BRIXIUS K, SCHOENBERGER S, LADAGE D, KNIGGE H, FALKOWSKI G, HELLMICH M, GRAF C, LATSCH J, MONTIE GL, PREDE GL, BLOCH W: Long-term endurance exercise decreases the antiangiogenic endostatin signaling in adipose men aged between 50-60 years. Br J Sports Med 42: 126-129, 2008.

BUCCIARELLI LG, WENDT T, RONG L, LALLA E, HOFMANN MA, GOOVA MT, TAGUCHI A, YAN SF, YAN SD, STERN DM, SCHMIDT AM: RAGE is a multiligand receptor of the immonoglobulin superfamily: implications for homeostasis and chronic disease. Cell Mol Life Sci 59: 1117-1128, 2002.

BÜTTNER P, MOSIG S, LECHTERMANN A, FUNKE H, MOOREN FC: Exercise affects the gene expression profile of human white blood cells. J Appl Physiol 102: 26-36, 2007.

CARMELI E, MOAS M, LENNON S, POWERS SK: High intensity exercise increases expression of matrix metalloproteinases in fast skeletal muscle fibres. Exp Physiol 90: 613-619, 2005.

CÍFKOVÁ R, ŠKODOVÁ Z: Changes of risk factors in the population and a decrease of cardiovascular mortality (in Czech). JACC-CZ 4: 77-80, 2002.

FALCONE C, EMANUELE E, D'ANGELO A, BUZZI MP, BELVITO C, CUCCIA M, GEROLDI D: Plasma levels of soluble receptor for advanced glycation end products and coronary artery disease in nondiabetic men. Arterioscler Tromb Vasc Biol 25: 879-882, 2005.

FOOTE RS, PEARLMAN JD, SIEGEL AH, YEO KT: Detection of exercise-induced ischemia by changes in B-type natriuretic peptides. J Am Coll Cardiol 44: 1980-1987, 2004.

GELUK CA, POST WJ, HILLEGE HL, TIO RA, TIJSSEN JG, VAN DIJK RB, DIJK WA, BAKKER SJ, DE JONG PE, VAN GILST WH, ZIJLSTRA F: C-reactive protein and angiographic characteristics of stable and unstable coronary artery disease: data from the prospective PREVEND cohort. Atherosclerosis 196: 372-382, 2008.

GELUK CA, TIO RA, TIJSSEN JG, VAN DIJK RB, DIJK WA, HILLEGE HL, DE JONG PE, VAN GILST WH, ZIJLSTRA F: Clinical characteristics, cardiac events and coronary angiographic findings in the prospective PREVEND cohort. Neth Heart J 15: 133-141, 2007.

GEROLDI D, FALCONE C, EMANUELE E, D'ANGELO A, CALCAGNINO M, BUZZI MP, SCIOLI GA, FOGARI R: Decreased plasma levels of soluble receptor for advanced glycation end-products in patients with essential hypertension. Hypertension 23: 1725-1729, 2005.

HESS OM, MC KENNA W, SCHULTHEISS HP: Myocardial disease. In: The ESC Textbook of Cardiovascular Medicine. CAMM AJ, LÜSCHER TF, SERRYUS PW (eds), Blackwell Publishing, Oxford, 2006, pp 453-515.

KALOUSOVÁ M, SULKOVÁ S, FIALOVÁ L, SOUKUPOVÁ J, MALBOHAN IM, ŠPAČEK P, BRAUN M, MIKULÍKOVÁ L, FORTOVÁ M, HOŘEJŠÍ M, TESǍ̌ V, ZIMA T: Glycoxidation and inflammation in chronic haemodialysis patients. Nephrol Dial Transplant 18: 2577-2581, 2003.

KALOUSOVÁ M, JÁCHYMOVÁ M, MESTEK O, HODKOVÁ M, KAZDEROVÁ M, TESAR V, ZIMA T: Receptor for advanced glycation end products-soluble form and gene polymophism in chronic haemodialysis patients. Nephrol Dial Transplant 22: 2020-2026, 2007.

KANEDA H, TAGUCHI J, OGASAWARA K, AIZAWA T, OHNO M: Increased level of advanced oxidation protein products in patients with coronary artery disease. Atherosclerosis 162: 221-225, 2002.

KULLO IJ, KHALEGHI M, HENSRUD DD: Markers of inflammation are inversely associated with $\mathrm{VO}_{2}$ max in asymptomatic men. J Appl Physiol 102: 1374-1379, 2007.

MAISEL AS, KOON J, KRISHNASWAMY P, KAZENEGRA R, CLOPTON P, GARDETTO N, MORRISEY R, GARCIA A, CHIU A, DE MARIA A: Utility of B-natriuretic peptide as a rapid point of care test for screeining patients undergoing echocardiography to determine left ventricular dysfunction. Am Heart $J$ 141: 367-374, 2001. 
MCQUIBBAN GA, GONG JH, TAM EM, MCCULLOCH CA, CLARK-LEWIS I, OVERALL CM: Inflammation dampened by gelatinase A cleavage of monocyte chemoattractant protein-3. Science 289: 1202-1206, 2000.

NAKAMURA K, YAMAGISHI S, ADACHI H, KURITA-NAKAMURA Y, MATSUI T, YOSHIDA T, SATO A, IMAIZUMI T: Elevation of soluble form of receptor for advanced glycation end products (sRAGE) in diabetic subjcts with coronary artery disease. Diabetes Metab Res Rev 23: 368-371, 2007.

NEUFELD G, COHEN T, GENGRINOVITCH S, POLTORAK Z: Vascular endothelial growth factor (VEGF) and its receptors. FASEB J 13: 9-22, 1999.

PARKS WC, MECHAM RP: Matrix Metaloproteinasis. Academic Press, San Diego, 1998.

PIALOUX V, MOUNIER R, PONSOT E, ROCK E, MAZUR A, DUFOUR S, RICHARD R, RICHALET JP, COUDERT J, FELLMANN N: Effects of exercise and training in hypoxia on antioxidant/pro-oxidant balance. Eur J Clin Nutr 60: 1345-1354, 2006.

POHOST GM, O'ROURKE RA, BERMAN DS: Imaging in Cardiovascular Disease. Lippincott Williams and Wilkins, Philadelphia, 2000.

RACEK J, RACKOVÁ M: Less common risk factors of atherogenesis - homocysteine, lipoprotein (a) and C-reactive protein (in Czech). Cas Lek Cesk 141: 605-609, 2002.

RIDKER PM: Clinical application of C-reactive protein for cardiovascular disease detection and prevention. Circulation 107: 363-369, 2003.

SHIMIZU Y, SHAW S, GRABER N, GOPAL TV, HORGAN KJ, VAN SEVENTER GA, NEWMAN W: Activationindependent binding of human memory T cells to adhesion molecule ELAM-I. Nature 349: 799-802, 1991.

SIGNORELLI SS, MAZZARINO MC, Di PINO L, MALAPONTE G, PORTO C, PENNISI G, MARCHESE G, COSTA MP, DIGRANDI D, CELOTTA G, VIRGILIO V: High circulating levels of cytokines (IL-6 and TNF $\alpha$ ), adhesion molecules (VCAM-1 and ICAM-1) and selectins in patients with peripheral arterial disease at rest and after a treadmill test. Vasc Med 8:15-19, 2003.

STERN S: State of art in stress testing and ischemia monitoring. Card Electrophysiol Rev 6: 204-208, 2002.

SUHR F, BRIXIUS K, DE MARÉES M, BÖLCK B, KLEINÖDER H, ACHTZEHN S, BLOCH W, MESTER J: Effects of short-term vibration and hypoxia during high-intensity cycling exercise on circulating levels of angiogenic regulators in humans. J Appl Physiol 103: 464-483, 2007.

SUNG KC, SUH JY, KIM BS, KANG JH, KIM H, LEE MH, PARK JR, KIM SW: High sensitivity C-reactive protein as an independent risk factor for essential hypertension. Am J Hypertens 16: 429-433, 2003.

VANZETTO G, JACON P, CALIZZANO A, NEUDER Y, FAURE P, FAGRET D, MACHECOURT J: N-terminal pro-brain natriuretic peptide predicts myocardial ischemia and is related to postischemic left-ventricular dysfunction in patients with stable coronary artery disease. J Nucl Cardiol 14: 835-842, 2007.

WIN HK, CHANG SM, RAIZNER M, SHAH G, AL BASKY F, DESAI U, PLANA JC, MAHMARIAN JJ, QUINONES MA, ZOGHBI WA: Percent change in B-type natriuretic peptide levels during treadmill exercise as a screening test for exercise-induced myocardial ischemia Am Heart $J$ 4: 695-700, 2005.

WITKO-SARSAT V, FRIEDLANDER M, CAPEILLÈRE-BLANDIN C, NGUYEN-KHOA T, NGUYEN AT, ZINGRAFF J, JUNGERS P, DESCAMPS-LATSCHA B: Advanced oxidation protein products as a novel marker of oxidative stress in uremia. Kidney Int 49: 1304-1313, 1996.

WU TC, LEU HB, LIN WT, LIN CP, LIN SJ, CHEN JW: Plasma matrix metalloproteinase-3 level is an independent prognostic factor in stable coronary artery disease. Eur J Clin Invest 35: 537-545, 2005. 